\title{
The beneficial effect of physical activity on cognitive function in community-dwelling older persons with locomotive syndrome
}

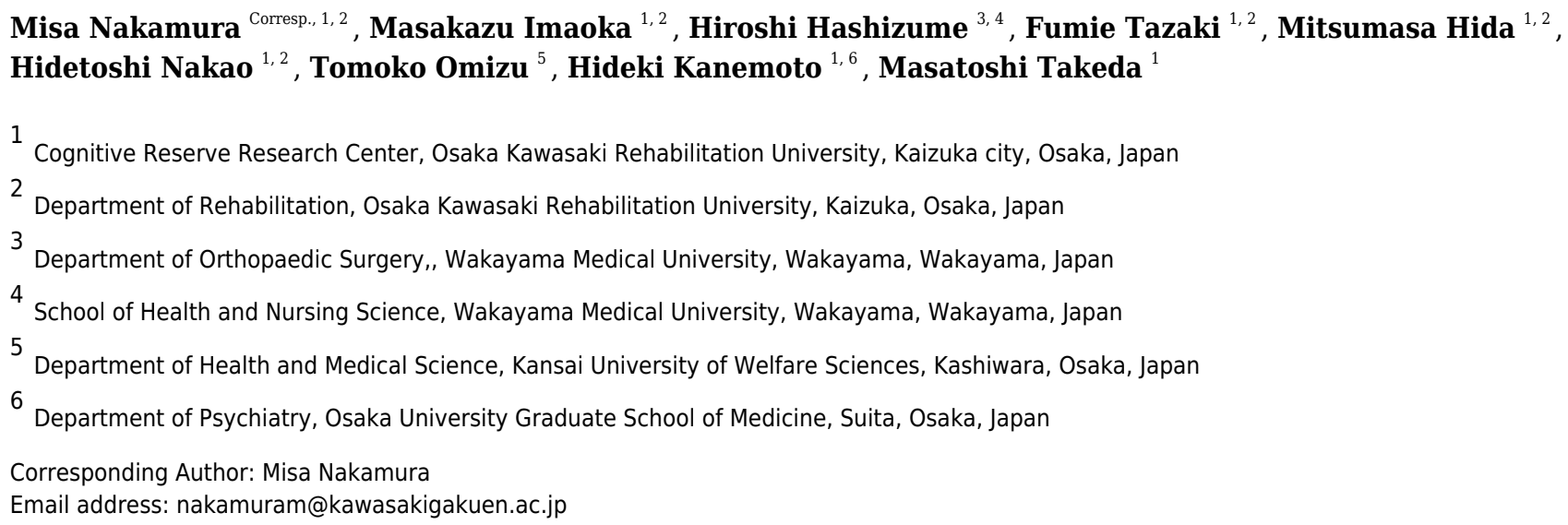

Background. Cognitive decline is closely related to motor decline. Locomotive syndrome (LS) is defined as a state associated with a high risk of requiring support because of locomotive organ disorders, and can be evaluated using a questionnaire. This study aimed to clarify the effectiveness of daily goal-targeted exercise on cognitive function in two different populations classified by scores on the Locomo 25 questionnaire. Methods. Seventy community-dwelling older people who participated in a 13-week health class were divided into two populations based on Locomo 25 scores: $<7$ (non-LS) and $\geq 7$ (LS). Participants were presented with a daily target steps and worked towards that goal. Cognitive function was evaluated using the Japanese version of Addenbrooke's Cognitive Examination-Revised (ACE-R). Average daily physical activity (exercise [Ex]) for 13 weeks was measured using a portable activity meter. Depression status was assessed using the Geriatric Depression Scale (GDS-15). Results. No significant differences were observed in age, years of education, body mass index, smooth muscle mass index, GDS-15 scores, or ACE-R scores between the non-LS and LS populations. Multiple logistic regression analysis showed that Ex (odds ratio $=5.01, p=0.002$ ) for 13 weeks was significantly associated with increased cognitive function in the LS population. The Ex threshold for the increase in cognitive function based on receiver operating curve analysis was 2.29 metabolic equivalents of task (METs) $\times \mathrm{h}($ METs.h/day) $(\mathrm{p}=0.047)$ in the LS population. After 13 weeks, ACE-R scores were significantly higher in the Ex $\geq 2.29$ than in the Ex $<2.29$ METs.h/day group $\left(p=0.024, h_{p}{ }^{2}=0.241\right)$ in the LS population based on two-way analysis 
of covariance. Furthermore, a significant increase in the ACE-R memory domain was seen in the Ex $\geq 2.29$ group $\left(p=0.035, \eta_{p}^{2}=0.213\right.$ ). Conclusions. These results suggest that Ex $\geq 2.29 \mathrm{METs} \cdot \mathrm{h} /$ day is important for improving cognitive function in LS populations with decreased locomotor function. 


\section{Manuscript Title}

2 The beneficial effect of physical activity on cognitive function in community-dwelling older

3 persons with locomotive syndrome

4

5 Misa Nakamura ${ }^{1,2}$, Masakazu Imaoka ${ }^{1,2}$, Hiroshi Hashizume ${ }^{3,4}$, Fumie Tazaki ${ }^{1,2}$,

6 Mitsumasa Hida ${ }^{1,2}$, Hidetoshi Nakao ${ }^{1,2}$, Tomoko Omizu ${ }^{5}$, Hideki Kanemoto ${ }^{1,6}$, Masatoshi

7 Takeda $^{1}$

8

9

${ }^{1}$ Cognitive Reserve Research Center, Osaka Kawasaki Rehabilitation University, Kaizuka,

10 Osaka, Japan

$11{ }^{2}$ Department of Rehabilitation, Osaka Kawasaki Rehabilitation University, Kaizuka, Osaka,

12 Japan

$13{ }^{3}$ Department of Orthopaedic Surgery, Wakayama Medical University, Wakayama, Wakayama, 14 Japan

$15{ }^{4}$ School of Health and Nursing Science, Wakayama Medical University, Wakayama, Wakayama, 16 Japan

17 5epartment of Health and Medical Science, Kansai University of Welfare Sciences, Kashiwara, 18 Osaka, Japan

19 ' ${ }^{6}$ epartment of Psychiatry, Osaka University Graduate School of Medicine, Suita, Osaka, Japan 20

21 Corresponding Author:

22 Misa Nakamura

23 Mizuma 159, Kaizuka, Osaka 597-0104, Japan

24 E-mail address: nakamuram@kawasakigakuen.ac.jp 


\section{Abstract}

27 Background. Cognitive decline is closely related to motor decline. Locomotive syndrome (LS)

28 is defined as a state associated with a high risk of requiring support because of locomotive organ

29 disorders, and can be evaluated using a questionnaire. This study aimed to clarify the

30 effectiveness of goal-targeted exercise on cognitive function in two different populations

31 classified by scores on the Locomo 25 questionnaire.

32 Methods. Seventy community-dwelling older people who participated in a 13-week health class

33 were divided into two populations based on Locomo 25 scores: $<7$ (non-LS) and $\geq 7$ (LS).

34 Participants were presented with a daily target steps and worked toward that goal. Cognitive

35 function was evaluated using the Japanese version of Addenbrooke's Cognitive Examination-

36 Revised (ACE-R). Average daily physical activity (exercise [Ex]) for 13 weeks was measured

37 using a portable activity meter. Depression status was assessed using the Geriatric Depression

38 Scale (GDS-15).

39 Results. No significant differences were observed in age, years of education, body mass index,

40 smooth muscle mass index, GDS-15 scores, or ACE-R scores between the non-LS and LS

41 populations. Multiple logistic regression analysis showed that $\operatorname{Ex}($ odds ratio $=5.01, \mathrm{p}=0.002$ )

42 for 13 weeks was significantly associated with increased cognitive function in the LS population.

43 The Ex threshold for the increase in cognitive function based on receiver operating curve

44 analysis was 2.29 metabolic equivalents of task (METs) $\times \mathrm{h}(\mathrm{METs} \cdot \mathrm{h} /$ day $)(\mathrm{p}=0.047)$ in the LS

45 population. After 13 weeks, ACE-R scores were significantly higher in the Ex $\geq 2.29$ than in the

Ex $<2.29 \mathrm{METs} \cdot \mathrm{h}$ /day group $\left(\mathrm{p}=0.024, \eta_{\mathrm{p}}{ }^{2}=0.241\right)$ in the LS population based on two-way analysis of covariance. Furthermore, a significant increase in the ACE-R memory domain was

48 seen in the Ex $\geq 2.29$ group $\left(\mathrm{p}=0.035, \eta_{\mathrm{p}}{ }^{2}=0.213\right)$.

49 Conclusions. These results suggest that $\mathrm{Ex} \geq 2.29 \mathrm{METs} \cdot \mathrm{h} /$ day is important for improving cognitive function in LS populations with decreased locomotor function. 


\section{Introduction}

53 In Japan, over $26 \%$ of the population was aged $\geq 65$ years as of 2015 , and by 2040 , the

54 proportion of older people (> 75 years) is expected to surpass $20 \%$; therefore, Japan is becoming 55 a super-aging society (Statistics Bureau of Japan, Elderly population, 2018). Under these 56 circumstances, to realize a society with healthy longevity, it is important to prevent the aged 57 from falling into dysfunction or requiring nursing care. It has been reported that musculoskeletal 58 diseases such as bone fractures and osteoporosis rank first, and dementia ranks third, in terms of

Locomotive syndrome (LS) was proposed by the Japanese Orthopaedic Association in 2007 as a state with a high risk of requiring health-care support or nursing care because of problems associated with locomotion. Some causes of LS include reduced muscle strength and balance associated with aging and locomotive pathologies such as sarcopenia, osteoarthritis, and osteoporosis (Nakamura, 2008; Momoki et al., 2017). LS has also been found to be closely related to frailty (Yoshimura et al., 2019). In recent years, we have analyzed cross-sectional studies on factors related to LS in community-dwelling older people and found that LS is associated with motor function (Nakamura et al., 2015), body mass index (BMI) (Nakamura et al., 2016), depression (Nakamura et al., 2017a), cognitive function (Nakamura et al., 2017b), and subjective oral dysfunction (Nakamura et al., 2021). Several studies on LS and motor function have been conducted (Ikemoto \& Arai, 2018). The proportion of the population with LS (47 million) in Japan is estimated to be more than twice that with metabolic syndrome (20 million) (Yoshimura et al., 2009; Ministry of Health, Labour and Welfare, 2016). One of the methods used to evaluate the severity of LS is the Locomo 25 questionnaire, a 25 -item LS screening tool that measures the degrees of physical pain, ability to carry out activities of daily living (ADL), sociality, and active living (Nakamura, 2008; Wang et al., 2020). A Locomo 25 score of $\geq 7$ indicates LS (Japan Orthopaedic Association, 2015).

Adequate exercise and nutrition have been widely suggested as preventive measures for cognitive function decline. In addition, the state at which walking function and cognitive function are reduced at the pre-stage of dementia is called "motor cognitive risk syndrome" (Verghese et al., 2014), and the clinical significance of evaluating motor function in this way is being increasingly recognized. However, it remains unclear to what extent motor therapy is effective to prevent cognitive decline among people with reduced motor function. In addition, many health classes have introduced uniform exercise activities for their participants, but the results are somewhat unclear. We previously identified a strong relationship between Locomo 25 and Mini-Mental State Examination scores, which are used to evaluate cognitive function, in older women living independently in the community: a Locomo 25 score of 6 points was the cutoff value for normal cognitive function, whereas a score of $\geq 6$ indicated a higher risk for cognitive decline (Nakamura et al., 2017b). These findings suggest that cognitive decline would be prevented if musculoskeletal function could be recovered-i.e., a reduction in the severity of LS - by some kind of intervention in the early stage using Locomo 25 as an index. It has been reported that LS-induced back pain improves with exercise (Hashizume et al., 2014), and that 
92 exercise interventions for osteoarthritis improve ADL (Penninx et al., 2001). Considering the

93 findings from these previous studies, establishing preventive measures linking cognitive function

94 with LS was considered to be potentially effective for reducing the need for long-term care.

95 Physical activity refers to all body movements by the skeletal muscles that expend energy, 96 and includes whole-body endurance, muscular strength, balance ability, and flexibility. By

97 contrast, exercise is a planned, intentional, and continuous type of physical activity aimed at

98 maintaining and improving physical strength. Physical activity is associated with mortality, in

99 that higher levels of physical activity decrease the risk of death (Gregg et al., 2003). In addition,

100 cognitive function has been reported to be closely related to motor function (Maruya et al.,

101 2018), and both exercise and physical activity have been shown to be effective for increasing

102 cognitive reserve for the prevention of dementia and for reducing brain damage and

103 neuroinflammation (Livingston et al., 2020).

104

105

106

107

108

109

110

111

112

113

114

115

116

117

118

119

120

121

122

123

124

125

126

127

128

129

130

Given this background, the purposes of this study were to categorize community-dwelling older people based on the presence or absence of LS and to clarify the effectiveness of daily goal-targeted exercise on cognitive function in two different populations classified by Locomo 25 scores.

\section{Materials \& Methods}

\section{Participants}

This study was conducted in Kaizuka city, Osaka Prefecture, from January to April 2019. The study participants were recruited by placing a recruitment leaflet in the local newspaper or posting it at the city hall. The exclusion criteria were: 1 ) $<60$ years of age; 2 ) previously diagnosed with dementia; 3) having a cardiac pacemaker; and 4) had stopped exercising on the advice of a physician. All applicants participated in a once-weekly 13-week exercise class cohosted by Kaizuka city and Osaka Kawasaki Rehabilitation University. A previous study on the effects of a once-weekly 90-min walking program for community-dwelling older adults reported improved cognitive function after about 3 months (Maki et al., 2012); therefore, the intervention period in the present study was set to 13 weeks. The exercise class was conducted once a week ( $1 \mathrm{~h}$ per session) for 13 weeks by a certified physical therapist. The contents of the class included 15 min of intellectual tasks and 45 min of exercise tasks, such as soft gymnastics and light dancing. At the beginning of the study, a wireless activity meter with three-axis accelerometer sensors (AM510N; ACOS Co., Ltd., Nagano, Japan) was handed out to each person. This activity meter has been proven to have the same accuracy as that from other companies (personal communication with ACOS Co.). The target values were 6,700 steps per day for men and 5,900 steps per day for women, which are the values proposed by the Ministry of Health, Labour and Welfare of Japan for the prevention of lifestyle-related diseases for people aged $\geq 70$ years (Ministry of Health, Labour and Welfare, Healthy Japan 21). The measurements described below were performed before participation (baseline) and after a 13-week intervention. A selfadministered questionnaire on education history was also implemented. 
131

132

133

134

135

136

137

138

139

140

141

142

143

144

145

146

147

148

149

150

151

152

153

154

155

156

157

158

159

160

161

162

163

164

165

166

167

168

169

170

In total, 98 individuals participated in the baseline measurement. During the 13-week study period, one patient was hospitalized and 15 discontinued. After 13 weeks, 82 participants remained, among whom, four who had lost their activity meter, five who had not answered the questionnaire completely, and three who had a daily activity level (exercise [Ex]) $\geq 7.0$ (metabolic equivalents of task (METs) $\times \mathrm{h}($ METs $\cdot h)$ were excluded. Finally, data from 70 participants (20\% men; mean age [standard deviation], 74.71 [5.26] years; age range, 63-91 years) were analyzed. A flowchart is shown in Figure 1. This study was reviewed and approved by the Ethics Committee of Osaka Kawasaki Rehabilitation University (approval No.: OKRU29A015), and carried out in accordance with the Declaration of Helsinki. Prior to the start of the survey, written informed consent was obtained from all participants. Participants with cognitive decline were permitted to ask their spouse, children, or other relatives to answer on their behalf.

\section{Measurement of variables}

BMI was calculated as the weight in kilograms divided by the height in meters squared. Skeletal muscle mass index (SMI) was measured using a bioelectrical impedance analysis (BIA) device (InBody 270; InBody Japan Co., Ltd., Tokyo, Japan) at 20 and 1,000 kHz while the participants were wearing normal indoor clothing without socks and shoes. All participants were instructed to grasp the handles of the BIA device and stand on electrodes contacting the bottoms of their feet. Physical activity was measured using a wireless activity meter (AM510N; ACOS Co., Ltd., Nagano, Japan) that the participants attached to their pants for 13 weeks and removed only when taking a bath. After 13 weeks, daily Ex (METs $h$ ) for 13 weeks from the activity meter was read by a contactless integrated circuit card reader (Ferica RC-S380/S; Sony Co., Tokyo, Japan) and the data were transferred to an Excel file. The average Ex per day was calculated by dividing the total Ex for 13 weeks by 91 days.

\section{Evaluation of depression}

Depression has been reported to be related to LS (Nakamura et al., 2017b) and cognition (Byers et al., 2011); therefore, we considered that depression could be a confounding factor. Depression status was assessed using the 15-item Geriatric Depression Scale (GDS-15), a widely used international instrument for depression screening in the general geriatric population with confirmed reliability and validity (Demura et al., 2006). Each item on the GDS-15 is measured using a yes/no questionnaire. All 15 items are scored as either 0 or 1 , with the total score ranging from 0 to 15. Scores $\geq 5$ are evaluated as depression (Shiekh \& Yesavage, 1986).

\section{Evaluation of cognitive function}

Cognitive function was evaluated using the Japanese version of Addenbrooke's Cognitive Examination-Revised (ACE-R) (Mioshi et al., 2006; Hashimoto, 2010), which is a revised version of the original ACE (Mathuranath et al., 2000). The ACE-R is strongly correlated with Clinical Dementia Rating (CDR) scale and is more accurate than the Mini-Mental State Examination, which is widely used internationally for the detection of mild cognitive impairment 
171 (MCI) (Yoshida et al., 2011). The ACE-R consists of the following five cognitive areas: attention 172 and orientation (18 points), memory (26 points), language fluency (14 points), language (26 173 points), and visuospatial cognition (16 points). A perfect score on the ACE-R is 100 points 174 (Supplementary Table S1), while a score of $\geq 89$ is normal, a score of 83-88 indicates MCI, and 175 a score of $\leq 82$ indicates dementia (Yoshida et al., 2011, Yoshida et al., 2012). The ACE-R was 176 conducted in a one-on-one face-to-face manner. Version A was used at baseline, and version B at after 13 weeks. The classification, which is based on cognitive changes, was calculated by subtracting the baseline ACE-R score from that after 13 weeks. When this difference was $>0$, the participant was classified into the group with increased cognitive function, and when the difference was $\leq 0$, the participant was classified into the group with non-increased cognitive function.

182

\section{Assessment of LS status}

184

LS status was evaluated using the Locomo 25 score, which was previously known as the questionnaire composed of four questions about pain, 16 questions about ADL, three questions about social function, and two questions about mental health status during the last month (Seichi et al., 2012). All 25 items are scored from 0 (no impairment) to 4 (severe impairment), with the total score ranging from 0 to 100 . Higher scores indicate worse locomotive function, and a total score of $\geq 7$ points is evaluated as LS (Japan Orthopedic Association). Furthermore, in the LS risk classification, a Locomo 25 total score of 7-15 points indicates LS risk 1, 16-23 points LS risk 2 , and $\geq 24$ points LS risk 3 (Japan Orthopedic Association). The validity of the Locomo 25 was confirmed by demonstrating a significant correlation with the European Quality of Life Scale-5 Dimensions questionnaire (Seichi et al., 2012).

195

196

\section{Statistical analysis}

197

198

To compare numerical values between the two groups, the normality of distribution and homogeneity of variance were tested prior to comparison across groups. Student's $t$-test was used when assumptions of normal distribution and homogeneity of variance were fulfilled in both

201 groups, and Welch's $t$-test was used when the assumption of normal distribution was met, but not the assumption of homogeneity of variance. When the data were non-normally distributed, the

203 Wilcoxon signed-rank test was used. Pearson's chi-squared test was used to compare exercise habits between the non-LS and LS groups. To clarify the effect of Ex on cognitive improvement

205

206

207

208

209

210 after the 13-week intervention in the Non-LS and LS groups, the odds ratios (ORs) of measurements for an ACE-R score of $>0$ were calculated using logistic regression analysis adjusted for age. Ex used as independent variables, and an ACE-R score of $>0$ (increased cognitive function) was used as dependent variable. The Ex threshold score for discriminating between the increased and non-increased cognitive function groups was evaluated using receiver operating curve (ROC) analysis. The ORs of the cutoff values for increased cognitive function according to Ex were calculated using multiple logistic regression analyses adjusted for age. 
211 Two-way analysis of covariance (ANCOVA) using age and baseline as covariates was carried

212 out to compare $\triangle \mathrm{ACE}-\mathrm{R}$ scores and $\triangle \mathrm{ACE}-\mathrm{R}$ domain scores to determine the effect of Ex on

213 outcomes in the LS group after the 13-week study period. Partial eta-squared $\left(\eta_{\mathrm{p}}{ }^{2}\right)$ is the value of

214 the sum of squares (SSA) divided by the SSA plus the sum of squared errors of prediction. The

$215 \eta_{\mathrm{p}}^{2}$ values describe an effect size of 0.01 as small, 0.06 as medium, and 0.14 as large (Cohen,

216 1988). Two-way ANCOVA was conducted using SPSS Statistics software (version 26; IBM

217 Corp., Armonk, NY), and other statistical analyses using JMP 14 (SAS Institute, Cary, NC). All

218 statistical tests were two-tailed, and a significance level of 0.05 was used.

219

220

\section{Results}

221

The participants' age, years of education, BMI, SMI, GDS-15, ACE-R, Locomo 25 scores, and

222

223 exercise habits are shown in Table 1. No significant differences in age, years of education, BMI, SMI, or GDS-15 and ACE-R scores were found between the Non-LS and LS groups. Exercise habits before the start of the exercise class did not significantly differ between the two groups $(\mathrm{p}$

225

226 $=0.804$ ) (Table 1).

Table 2 shows a comparison of characteristics and changes in measurements from baseline to

227

228

229

230

231

232

233

234

235

236

237

238

239

240

241

242

243

244

245

246

247

248

249

250 13 weeks and physical activity levels for 13 weeks between non-increased cognitive function $(\triangle \mathrm{ACE}-\mathrm{R} \leq 0)$ and increased cognitive function $(\triangle \mathrm{ACE}-\mathrm{R}>0)$ in the non-LS and LS populations. In the LS population, Ex was significantly higher for increased compared with nonincreased cognitive function; however, no significant differences were observed for any changes in the non-LS population (Table 2).

Table 3 shows the results of logistic regression analysis adjusted for age and the ORs of each measurement, including GDS-15 scores and Ex in the non-LS and LS populations. The results showed that Ex was significantly associated with increased cognitive function (OR $=5.01,95 \%$ confidence interval $[\mathrm{CI}]=1.30-19.24 ; \mathrm{p}=0.002)$. However, no such significant association was detected in the non-LS population (Table 3).

ROC analysis was conducted in regard to Ex in the LS population. A threshold for discriminating between the non-increased and increased cognitive function groups was identified as follows. A high area under the ROC curve (AUC) value $(0.808, \mathrm{p}=0.047)$ was observed with an Ex threshold of $2.29 \mathrm{METs} \cdot \mathrm{h}$ /day in the LS population (Table 4). The ORs for the prevalence of increased cognitive function according to the threshold Ex values in the LS population are shown in Table 4 . In the LS population, the high Ex group ( $\geq 2.29 \mathrm{METs} \cdot \mathrm{h} /$ day $)$ showed increased cognitive function, with an $\mathrm{OR}$ of $21.94(95 \% \mathrm{CI}=2.11-228.12, \mathrm{p}=0.010)$ as determined by multiple logistic regression analysis adjusted for age (Table 4).

Table 5 shows a comparison between the two Ex groups among the LS population by twoway ANCOVA using age and baseline as the covariates. The $\triangle \mathrm{ACE}-\mathrm{R}$ scores were significantly higher in the Ex $\geq 2.29$ than in the Ex $<2.29 \mathrm{METs} \cdot \mathrm{h}$ /day group, with a large effect size $(\mathrm{p}=$ $\left.0.024, \eta_{\mathrm{p}}^{2}=0.241\right)$ (Table 5).

Table 6 shows a comparison of changes from baseline to 13 weeks in ACE-R domain scores between the Ex $<2.29$ and $\mathrm{Ex} \geq 2.29 \mathrm{METs} \cdot \mathrm{h}$ /day groups with LS by two-way ANCOVA using 
251

252

253

254

255

256

257

258

259

260

261

262

263

264

265

266

267

268

269

270

271

272

273

274

275

276

277

278

279

280

281

282

283

284

285

286

287

288

289

290

age and baseline as the covariates. Memory scores were significantly higher in the Ex $\geq 2.29$

than in the Ex $<2.29 \mathrm{METs} \cdot \mathrm{h} /$ day group, with a large effect size $\left(\mathrm{p}=0.035, \eta_{\mathrm{p}}{ }^{2}=0.213\right)$ (Table 6).

\section{Discussion}

The purposes of this study were to categorize community-dwelling older people based on the presence or absence of LS and to clarify the effectiveness of daily goal-targeted exercise on cognitive function in LS and non-LS groups. The results revealed a relationship between physical activity and cognitive function in the LS population; however, no such relationship was found in the non-LS population. The increased cognitive function during the 13-week study period was associated with higher average Ex in the LS population, and the ROC analysis showed a threshold of 2.29 METs-h/day. On the other hand, no significant relationship was found between Ex and cognitive function in the non-LS population. When the LS population was classified into $\mathrm{Ex}<2.29$ and Ex $\geq 2.29 \mathrm{METs} \cdot \mathrm{h} /$ day groups, a significant increase in ACE-R scores and a decrease in Locomo 25 scores were observed in the $\mathrm{Ex} \geq 2.29$ group. As exercise habits before the start of the intervention did not significantly differ between the non-LS and LS groups $(p=0.804$; Table 1$)$, the difference found in the amount of physical activity in this study was considered to be the result of the effort of each participant in aiming to achieve the target step count presented at the beginning of the study. From these results, it is considered that $\mathrm{Ex} \geq 2.29 \mathrm{METs} \cdot \mathrm{h} /$ day was effective in improving LS and restoring cognitive function in the LS population.

There have been many reports on the relationship between exercise/physical activity and events related to cognitive function (Livingston et al., 2020). A clinical study reported a correlation between low levels of motor function and high amyloid $\beta$ deposition (Tian et al., 2017). Cohort studies have reported that a high level of physical activity reduces the risk of cognitive decline and Alzheimer's disease (AD) (Warburton et al., 2010; Plassman et al., 2010; Wennberg et al., 2017). Thus, there are two aspects of a high level of physical activity: one suppresses or delays the development of $\mathrm{AD}$ pathology, and the other increases other cognitive functions independently of $\mathrm{AD}$ pathology, i.e., it compensates for impaired cognitive function and promotes high brain plasticity (Buchman et al., 2008). It is speculated that these mechanisms are involved in the relationship between physical activity and cognitive function identified in this study.

Although depression has been reported to be related to LS (Nakamura et al., 2017a) and cognition (Byers et al., 2011), in the present study, no relationship was found between GDS-15 scores at baseline or LS status and cognitive changes after 13 weeks, as shown in Tables 1 and 2. The reason for this was considered to be that the overall GDS-15 scores were low and cognitive function high in the participants in the present study.

Table 2 shows that the Locomo 25 score tended to decrease during the 13-week study period in the increased cognitive function group in the LS population, although no statistically significant difference was found. This result suggests that $\mathrm{Ex} \geq 2.29 \mathrm{METs} \cdot \mathrm{h} /$ day reduces the level of LS. Locomo 25 mainly includes questions about the degrees of physical pain, ADL, 
291

292

293

294

295

296

297

298

299

300

301

302

303

304

305

306

307

308

309

310

311

312

313

314

315

316

317

318

319

320

321

322

323

324

325

326

327

328

329

330

social function, and mental health. According to a recent survey by the Ministry of Health, Labour and Welfare of Japan (2016), chronic pain in the locomotive organs is severe, and usually at sites necessary for movement, such as the hip and lower limb joints, so pain is strongly associated with LS. Physical activity has been reported to be associated with body pain (Naugle et al., 2017), ADL (Wearing et al., 2020), and mental health (Chekroud et al., 2018), and exercise has been reported to improve low back pain (Hashizume et al., 2014) and ADL (Penninx et al., 2001). Therefore, it was considered that the decrease in Locomo 25 scores in the $\mathrm{Ex} \geq 2.29 \mathrm{METs} \cdot \mathrm{h} /$ day group with LS was due to an increase in physical activity, a decrease in pain, and an increase in the ability to carry out ADL.

According to the Ministry of Health, Labour and Welfare's "Physical Activity Standards for Health Promotion 2013" (2013), Ex $\geq 10$ METs $\cdot h /$ week should be maintained regardless of strength for health promotion among older people aged $\geq 65$ years. However, the results of the present study suggest that $\mathrm{Ex} \geq 16 \mathrm{METs} \cdot \mathrm{h} /$ week is needed to improve cognitive function; 10 METs $\cdot h /$ week had no effect on improving cognitive function in people with LS.

In the present study, a significant increase was observed in the memory score domain of the ACE-R in the group with $\mathrm{Ex} \geq 2.29 \mathrm{METs} \cdot \mathrm{h} /$ day in the LS population. It has been reported that moderate physical activity is positively correlated with hippocampal capacity, as is physical activity and memory (Makizako et al., 2015). It has also been reported that smaller hippocampal volume in the healthy aged is associated with severe acute and chronic pain (Zimmerman et al., 2009). Furthermore, a longitudinal cohort of older people found that persistent pain is associated with decreased memory and an increased likelihood of dementia (Whitlock et al., 2017). The results of the present study suggest that the LS population may have increased memory owing to increased physical activity and pain relief.

In this study, no relationship was found between physical activity and cognitive function in the non-LS population. Since non-LS groups have potentially high physical function, it may be necessary to set a high Ex target value for physical activity to affect cognitive function. Furthermore, factors other than physical activity, such as dietary patterns (Gillette-Guyonnet et al., 2013, Gu \& Scaneas, 2011), intellectual activity (Wang et al., 2002), and sleep patterns (Ma et al., 2020), may be involved in the recovery of cognitive function, so these should be investigated in the future.

This study did have several limitations. First, the number of study participants $(n=70)$ was small. Second, the criteria for LS in terms of Locomo 25 scores have two levels: $\geq 7$ points and $\geq$ 16 points. However, in this study, few people in the target population had a Locomo 25 score of $\geq 16$ points, so a score of $\geq 7$ was considered to indicate LS. In the future, exercise intervention times can be expected to be identified more accurately by conducting surveys on more participants and categorizing them into more severe and milder groups in the LS population. Third, it was not possible to separate clearly physical activity from exercise, so the content of the measured physical activity was not clear. Fourth, individuals who had been diagnosed with dementia in the hospital were excluded from the analysis in this study, but some were in the dementia category in the ACE-R assessment. In the future, it will be necessary to use a system in 
331 which the number of people in the cognitive function category is equalized at baseline between 332 the two groups. In addition, since minimal clinically important differences are unclear in the 333 ACE-R assessment, the differences in ACE-R scores before and after the intervention were used 334 as an index of cognitive change. It will therefore be necessary to consider criteria for "ACE-R 335 improvements" in the future.

336

\section{Conclusions}

338 In this study, community-dwelling older people were categorized based on the presence or 339 absence of LS as classified by Locomo 25 scores, and the effect of daily goal-targeted exercise 340 on cognitive function was clarified in the two groups. The results revealed a relationship between 341 physical activity and cognitive function in the LS population; however, no such relationship was

342 found in the non-LS population. ACE-R scores were significantly higher in the Ex $\geq 2.29$ than in 343 the $\mathrm{Ex}<2.29 \mathrm{METs} \cdot \mathrm{h} /$ day group in the LS population. Furthermore, a significant increase in the 344 ACE-R memory domain was seen in the Ex $\geq 2.29$ group. These results suggest that EX $2.29 \geq$ $345 \mathrm{METs} \cdot \mathrm{h} /$ day is important for improving cognitive function in LS populations with decreased 346 locomotor function. In the future, it will be important to analyze the effectiveness of exercise 347 together with detailed LS status and cognitive function categories under greater control.

348

\section{Acknowledgements}

350

351

352

353

The authors wish to thank Ms. Kaori Hamamura, Ms. Hiroko Fujiwara, and Mr. Yuji Tsukuda of the Kaizuka City Office, Welfare Department Elderly Care section, and Ms. Ritsuko Tanaka and the many students at Osaka Kawasaki Rehabilitation University for their assistance with examinations and measurements. 


\section{References}

356

357

358

359

360

361

362

363

364

365

366

367

368

369

370

371

372

373

374

375

376

377

378

379

380

381

382

383

384

385

386

387

388

389

390

391

392

393

Buchman AS, Yu L, Wilson RS, Lim A, Dawe RJ, Gaiteri C, Leurgans SE, Schneider JA, Bennett DA. 2019. Physical activity, common brain pathologies, and cognition in communitydwelling older adults. Neurology 92:e811-822

Byers AL, Yaffe K. Depression and risk of developing dementia. 2011. Nature Reviews Neurology 7:323-331

Chekroud SR, Gueorguieva R, Zheutlin AB, Paulus M, Krumholz HM, Krystal JH, Chekroud AM. 2018. Association between physical exercise and mental health in 12 million individuals in the USA between 2011 and 2015: a cross-sectional study. The Lancet Psychiatry 5:739-746

Cohen J. 1988. Statistical Power Analyses for the Behavioral Sciences. 2nd ed. Hillsdale, NJ: Lawrence Erlbaum Associates

Demura S, Sato S, Tada N, Matsuzawa J, Hamasaki H. 2006. Agreement in depression determination among four self-rating depression scales applied to Japanese communitydwelling elderly. Environmental Health and Preventive Medicine 11:177-183

Gillette-Guyonnet S, Secher M, Vellas B. 2013. Nutrition and neurodegeneration: epidemiological evidence and challenges for further research. British Journal of Clinical Pharmacology 75:738-755

Gregg EW, Cauley JA, Stone K, Thompson TJ, Bauer DC, Cummings SR, Ensrud KE. 2003. Relationship of changes in physical activity and mortality among older women. Journal of the American Medical Associatation 289:2379-2386

$\mathrm{Gu} \mathrm{Y}$ and Scaneas N. 2011. Dietary pattens in Alzheimer's desease and cognitive aging. Current Altzheimer Research 8:510-519

Hashimoto R. A Japanese version of the ACE-R, an appendix for the Japanese edition. In: Mori E, editor. Japanese Edition of Hodges JR's Cognitive Assessment for Clinicians. ed 2. Tokyo: Shinko Igaku Shuppansha; 2010. p. 285-301

Hashizume H, Yoshimura N, Nagata K, Miyazaki N, Ishimoto Y, Nishiyama R, Oka H, Yamada H, Yoshida M. 2014. Development and evaluation of a video exercise program for locomotive syndrome in the elderly. Modern Rheumatology 24:250-257

Ikemoto T, Arai YC. 2018. Locomotive syndrome: clinical perspectives. Clinical Interventions in Aging 13:819-827 Review

Japan Orthopedic Association. Japan Locomo Challenge Promotion Conference Website Available at https://locomo-joa.jp/check/judge/ [in Japanese] (accesses 10 Jan 2020)

Livingston G, Huntley J, Sommerlad A, Ames D, Ballard C, Banerjee S, Brayne C, Burns A, Cohen-Mansfield J, Cooper C, Costafreda SG, Dias A, Fox N, Gitlin LN, Howard R, Kales HC, Kivimäki M, Larson EB, Ogunniyi A, Orgeta V, Ritchie K, Rockwood K, Sampson EL, Samus Q, Schneider LS, Selbæk G, Teri L, Mukadam N. 2020. Dementia prevention, intervention, and care: 2020 report of the Lancet Commission. Lancet 396:416-446

Ma Y, Liang L, Zheng F, Shi L, Zhong B, Xie W. 2020. Association between sleep duration and cognitive decline. JAMA Network Open, 3:e2013573

Peer) reviewing PDF | (2020:11:55596:2:0:NEW 13 Sep 2021) 
394

395

396

397

398

399

400

401

402

403

404

405

406

407

408

409

410

411

412

413

414

415

416

417

418

419

420

421

422

423

424

425

426

427

428

429

430

431

432

Maki C, Ura C, Yamaguchi T, Murai T, Isahai M, Kaiho A, Yamagami T, Tanaka S, Miyamae F, Sugiyama M, Awata S, Takahashi R, Yamaguchi H. 2012. Effects of intervention using a community-based walking program for prevention of mental decline: a randomized controlled trial. Journal of the American Geriatrics Society 60; 505-510

Makizako H, Liu-Ambrose T, Doi T, Park H, Tsutsumimoto K, Uemura K, Suzuki T. 2015. Moderate-intensity physical activity, hippocampal volume, and memory in older adults with mild cognitive impairment. Journal of Gerontology Series A Biological Sciences and Medical Sciences 70:480-486

Maruya K, Fujita H, Arai T, Hosoi T, Ogiwara K, Moriyama S, Ishibashi H. 2018. Identifying elderly people at risk for cognitive decline by using the 2-step test. Journal of Physical Therapy Science 30:145-149

Mathuranath, PS, P J Nestor, G E Berrios, W Rakowicz, J R Hodges. 2000. A brief cognitive test battery to differentiate Alzheimer's disease and frontotemporal dementia. Neurology 55: 1613-1620

Ministry of Health, Labour and Welfare. Measures for national health Promotion, 2016. Ref-70. http://www.mhlw.go.jp/english/wp/wp-hw2/part2/p3_0024.pdf. (accesses 22 Sept 2016.) Ministry of Health, Labor and Welfare:Physical activity standards for health promotion 2013. Available at http://www. Mhlw. Go. Jp/stL/houdou/2r9852000002xple-att/2r9852000002xpqt. Pdf, 2013 (accesses 5 Jan 2020)

Ministry of Health, Labor and Welfare : Overview of the 2016 Basic Survey on National Life. Available at http://www, mhlw. Go. jp/toukei/saikin/hw/k-tyosa/k-tyosal6/index. htm1, 2017 (accesses 5 Jan 2020)

Ministry of Health, Labour and Welfare, Healthy Japan21, Physical activity and exercise. Available at https://www.mhlw.go.jp/www1/topics/kenko21_11/b2.html\#A21 (accessed 2 Nov 2018)

Mioshi E, Dawson K, Mitchell J, Arnold R, Hodges JR. 2006. The Addenbrooke's Cognitive Examination Revised (ACE-R): a brief cognitive test battery for dementia screening. International Journal of Geriatric Psychiatry 21:1078-1085

Momoki C, Habu D, Ogura J, Tada A, Hasei A, Sakurai K, Watanabe H. 2017. Relationships between sarcopenia and household status and locomotive syndrome in a community-dwelling elderly women in Japan. Geriatrics \& Gerontology International 17:54-60

Nakamura K. 2008. A "super-aged" society and the "locomotive syndrome" Journal of Orthopaedic Science 3:1-2

Nakamura M, Hashizume H, Oka H, Okada M, Takakura R, Hisari A, Yoshida M, Utsunomiya H. 2015. Physical Performance Measures Associated with Locomotive Syndrome in MiddleAged and Older Japanese Women. Journal of Geriatric Physical Therapy 38:202-207

Nakamura M, Kobashi Y, Hashizume H, Oka H, Kono R, Nomura S, Maeno A, Yoshida M, Utsunomiya H. 2016. Locomotive syndrome is associated with body composition and cardiometabolic disorders in elderly Japanese women. BMC Geriatrics 16:166

Peer] reviewing PDF | (2020:11:55596:2:0:NEW 13 Sep 2021) 
433 Nakamura M, Hashizume H, Nomura S, Kono R, Utsunomiya H. 2017a. The Relationship 434 between Locomotive Syndrome and Depression in Community-Dwelling Elderly People. 435 Current Gerontology and Geriatrics Research 2017:4104802 436 Nakamura M, Tazaki F, Nomura K, Takano T, Hashimoto M, Hashizume H, Kamei I. 2017b. 437 Cognitive impairment associated with locomotive syndrome in community-dwelling elderly 438 women in Japan. Clinical Interventions in Aging 12:1451-1457

Nakamura M, Imaoka M, Nakao H, Hida M, Tazaki F, Imai R, Utsunomiya H, Hashizume H. 2021. Association between subjective oral dysfunction and locomotive syndrome in community-dwelling older adults. Scientific Reports 11:12591

Naugle KM, Ohlman T, Naugle KE, Riley ZA, Keith NR. 2017. Physical activity behavior predicts endogenous pain modulation in older adults. Pain 158:383-390

Penninx BW, Messier SP, Rejeski WJ, Williamson JD, DiBari M, Cavazzini C, Applegate WB, Pahor M. 2001. Physical exercise and the prevention of disability in activities of daily living in older persons with osteoarthritis. Archives of International Medicine 161:2309-2316

Plassman BL, Williams JW Jr, Burke JR, Holsinger T, Benjamin S. 2010. Systematic review: factors associated with risk for and possible prevention of cognitive decline in later life. Annals of Internal Medicine 153:182-193

Seichi A, Hoshino Y, Doi T, Ohe T, Izumida R, Yoshimura N, Iwaya T. 2012. Development of a screening tool for risk of locomotive syndrome in the elderly: the 25-question Geriatric Locomotive Function Scale. Journal of Orthopaedic Science 17:163-117

Shiekh J, Yesavage J. 1986. Clinical gerontologyv: a gutide to assessnment andintervention. In: Brink T., editor. Geriatric Depression Scale; Recent Findings and Development of a Short Version. New York, NY, USA: Howarth Press, 165-173

Statistics Bureau of Japan, Elderly population.2018. Available at https://www.stat.go.jp/data/topics/topi1131.html. (accessed 5 Jan 2020)

Tian Q, Resnick SM, Bilgel M, Wong DF, Ferrucci L, Studenski SA. 2017. $\beta$-Amyloid Burden Predicts Lower Extremity Performance Decline in Cognitively Unimpaired Older Adults. Journal of Gerontoogy Series A Biological Sciences and Medical Sciences 72:716-723 Verghese J, Annweiler C, Ayers E, Barzilai N, Beauchet O, Bennett DA, Bridenbaugh AS, Camicioli R, Capistrant B, Chatterji S, Cock AD, Ferrucci L, Giladi N, Guralnik JM, Hausdorff JM, Holtzer R, Kim KW, Kowal P, Kressig RW, Lim JY, Lord S, Meguro K, Odasso MM, Muir Hunter SW, Noone ML, Rochester L, Srikanth V, Wang C. 2014. Motoric cognitive risk syndrome: multicountry prevalence and dementia risk. Neurology 83:718-726

Wang C, Ikemoto T, Hirasawa A, Arai YC, Kikuchi S, Deie M. 2020. Assessment of locomotive syndrome among older individuals:a confirmatory factor analysis of the 25-question Geriatric Locomotive Function Scale. PeerJ 14;8:e9026

Wang HX, Karp A, Winblad B, Fratiglioni L. 2002. Late-life engagement in social and leisureactivities is associated with a decreased risk of dementia: a longitudinal study from the Kungsholmen project. American Journal of Epidemiology 155:1081-1087

Warburton DE, Charlesworth S, Ivey A, Nettlefold L, Bredin SS. 2010. A systematic review of

Peer) reviewing PDF | (2020:11:55596:2:0:NEW 13 Sep 2021) 
473 the evidence for Canada's Physical Activity Guidelines for Adults. International Journal of

474 Behavioral Nutrition and Physical Activity 7:39

475 Wearing J, Konings P, de Bie RA, Stokes M, de Bruin ED. 2020. Prevalence of probable

476 sarcopenia in community-dwelling older Swiss people --a cross-sectional study. BMC

477 Geriatrics 20:307

478 Wennberg AMV, Savica R, Hagen CER, Roberts RO, David S Knopman DS, Hollman JH, 479 Vemuri P, Jack Jr CR, Petersen RC, Mielke MM. 2017. Cerebral amyloid deposition is 480 associated with gait parameters in the Mayo Clinic Study of Aging. Journal of the American 481 Geriatrics Society 65:792-799

482 Whitlock EL, Diaz-Ramirez LG, Glymour MM, Boscardin WJ, Covinsky KE, Smith AK. 2017. 483 Association between persistent pain and memory decline and dementia in a longitudinal cohort 484 of elders. Journal of the American Medical Associatation Internal Medicine 177:1146-1153 485 Yoshida H, Terada S, Honda H, Ata T, Takeda N, Kishimoto Y, Oshima E, Ishihara T, Kuroda 486 S. 2011. Validation of Addenbrooke's cognitive examination for detecting early dementia in a 487 Japanese population. Psychiatry Research 185:211-214 488 Yoshida H, Terada S, Honda H, Kishimoto Y, Takeda N, Oshima E, Hirayama K, Osamu 489 Yokota O, Uchitomi Y 2012. Validation of the revised Addenbrooke's Cognitive Examination 490 (ACE-R) for detecting mild cognitive impairment and dementia in a Japanese population. Int 491 Psychogeriatrics 24:28-37

492 Yoshimura N, Muraki S, Oka H, Yoshida M, Enyo Y, Kagotani R, Hashizume H, Yamada H, 493 Ishimoto Y, Teraguchi M, Tanaka S, Kawaguchi H, Toyama Y, Nakamura K, Akune T. 2009. 494 Prevalence of knee osteoarthritis, lumbar spondylosis, and osteoporosis in Japanese men and 495 women: the research on osteoarthritis/osteoporosis against disability study. Journal of Bone 496 and Mineral Metabolism 27(5):620-628

497 Yoshimura N, Muraki S, Iidaka T, Oka H, Horii C, Kawaguchi H, Akune T, Nakamura K,

498 Tanaka S. 2019. Prevalence and co-existence of locomotive syndrome, sarcopenia, and frailty: 499 the third survey of Research on Osteoarthritis/Osteoporosis Against Disability (ROAD) study. $500 \quad J$ Bone and Mineral Metabolism 37:1058-1066 501 Zimmerman ME, Pan JW, Hetherington HP, Lipton ML, Baigi K, Lipton RB. 2009. 502 Hippocampal correlates of pain in healthy elderly adults: a pilot study. Neurology 73:1567$503 \quad 1570$ 


\section{Table $\mathbf{1}$ (on next page)}

Comparisonof measurements at baseline and physical activity levels during the 13-week studyperiod and between the non-LS and LS populations.

All values are shown as mean (standard deviation) or prevalence (percentage). Non-LS, non-locomotive syndrome; LS, locomotive syndrome; BMI, body mass index; SMI, skeletal muscle mass index; GDS-15, Geriatric Depression Scale-15; ACE-R, Addenbrooke's Cognitive Examination-Revised. 
1 Table 1:

2 Comparison of measurements at baseline and physical activity levels during the 13-week 3 study period and between the non-LS and LS populations.

\begin{tabular}{|c|c|c|c|c|}
\hline & All & Non-LS & LS & $p$ \\
\hline $\mathrm{N}(\%$ men $)$ & $77770(20.0 \%)$ & $47(23.4 \%)$ & $23(13.0 \%)$ & \\
\hline Age (y) & $74.71(5.26)$ & $73.94(5.12)$ & $76.30(5.30)$ & 0.077 \\
\hline $\begin{array}{l}\text { Years of education } \\
\text { (y) }\end{array}$ & $12.27(2.35)$ & $12.43(2.33)$ & $11.96(2.40)$ & 0.436 \\
\hline $\operatorname{BMI}\left(\mathrm{kg} / \mathrm{m}^{2}\right)$ & $22.88(2.89)$ & $22.80(2.77)$ & $23.03(3.17)$ & 0.765 \\
\hline $\operatorname{SMI}\left(\mathrm{kg} / \mathrm{m}^{2}\right)$ & $6.00(0.90)$ & $6.07(0.89)$ & $5.85(0.92)$ & 0.333 \\
\hline GDS-15 (points) & $2.97(2.54)$ & $2.64(2.63)$ & $3.65(2.25)$ & 0.118 \\
\hline $\begin{array}{l}\text { ACE-R score } \\
\text { (points) }\end{array}$ & $90.37(8.15)$ & $91.28(7.29)$ & $88.52(9.58)$ & 0.186 \\
\hline $\begin{array}{l}\text { Locomo } 25 \text { score } \\
\text { (points) }\end{array}$ & $7.63(8.68)$ & $2.74(1.80)$ & $17.61(8.63)$ & $<0.0001$ \\
\hline \multicolumn{5}{|l|}{ Exercise } \\
\hline 7 days/week & $18.6 \%$ & $21.3 \%$ & $13.0 \%$ & 0.804 \\
\hline 5-6 days/week & $4.3 \%$ & $4.3 \%$ & $4.3 \%$ & \\
\hline 1-4 days/week & $60.0 \%$ & $59.6 \%$ & $60.9 \%$ & \\
\hline 0 days/week & $17.1 \%$ & $14.9 \%$ & $21.7 \%$ & \\
\hline
\end{tabular}

4 Notes. All values are shown as mean (standard deviation) or prevalence (percentage).

5 Non-LS, non-locomotive syndrome; LS, locomotive syndrome; BMI, body mass index; SMI, 6 skeletal muscle mass index; GDS-15, Geriatric Depression Scale-15; ACE-R, Addenbrooke's

7 Cognitive Examination-Revised.

8 


\section{Table 2 (on next page)}

\section{Comparisonof group characteristics and changes in values during the 13-week study period.}

All values are shown as mean (standard deviation) or prevalence (percentage). ${ }^{\dagger} p<0.05$ ( vs. ACE-R score $f 0$ in the non-LS group), ${ }^{\ddagger} p<0.05$ (vs. ACE-R score $f 0$ in the LS group). Non-LS, non-locomotive syndrome; LS, locomotive syndrome; D , change from baseline to 13 weeks; BMI, body mass index; SMI, skeletal muscle mass index; GDS-15, Geriatric Depression Scale-15; ACE-R, Addenbrooke's Cognitive Examination-Revised; Ex, daily exercise for 13 weeks; METs, metabolic equivalents of task. 
1 Table 2:

2 Comparison of group characteristics and changes in values during the 13-week study

3 period.

\begin{tabular}{|c|c|c|c|c|}
\hline & \multicolumn{2}{|c|}{ Non-LS } & \multicolumn{2}{|c|}{ LS } \\
\hline & $\begin{array}{l}\triangle \mathrm{ACE}-\mathrm{R} \text { score } \\
\quad \leq 0\end{array}$ & $\begin{array}{c}\Delta \mathrm{ACE}-\mathrm{R} \text { score } \\
\quad>0\end{array}$ & $\begin{array}{l}\triangle \mathrm{ACE}-\mathrm{R} \text { score } \\
\quad \leq 0\end{array}$ & $\begin{array}{c}\Delta \mathrm{ACE}-\mathrm{R} \text { score } \\
>0\end{array}$ \\
\hline $\mathrm{N}(\%$ men $)$ & $24(20.83 \%)$ & $23(26.09 \%)$ & $13(7.69 \%)$ & $10(20.00 \%)$ \\
\hline Age (y) & $74.46(4.81)$ & $73.39(5.48)$ & $74.62(4.31)$ & $78.50(5.87)$ \\
\hline $\begin{array}{l}\text { Years of } \\
\text { education }(y)\end{array}$ & $12.13(2.47)$ & $12.74(2.18)$ & $12.31(2.32)$ & $11.50(2.55)$ \\
\hline$\Delta \mathrm{BMI}\left(\mathrm{kg} / \mathrm{m}^{2}\right)$ & $-0.19(0.48)$ & $-0.29(0.29)$ & $-0.22(0.57)$ & $-0.32(0.53)$ \\
\hline$\Delta \mathrm{SMI}\left(\mathrm{kg} / \mathrm{m}^{2}\right)$ & $0.13(0.15)$ & $0.09(0.12)$ & $0.05(0.13)$ & $0.07(0.16)$ \\
\hline$\Delta$ GDS-15 (points) & $-0.54(1.14)$ & $-0.17(2.08)$ & $-0.92(2.25)$ & $-0.50(1.27)$ \\
\hline $\begin{array}{l}\triangle \mathrm{ACE}-\mathrm{R} \text { score } \\
\text { (points) }\end{array}$ & $-3.33(3.27)$ & $3.09(1.90) \dagger$ & $-3.92(3.62)$ & $4.30(2.87)^{\ddagger}$ \\
\hline $\begin{array}{l}\Delta \text { Locomo } 25 \text { score } \\
\text { (points) }\end{array}$ & $1.88(6.44)$ & $0.48(2.33)$ & $2.15(9.10)$ & $-1.50(8.36)$ \\
\hline Ex (METs·h/day) & $2.56(1.31)$ & $2.87(1.36)$ & $1.72(0.71)$ & $2.98(1.49)^{\dagger}$ \\
\hline
\end{tabular}

$4 \overline{\text { Notes. All values are shown as mean (standard deviation) or prevalence (percentage). }{ }^{\dagger} p<0.05}$

5 (vs. ACE-R score $\leq 0$ in the non-LS group), ${ }^{*} p<0.05$ (vs. ACE-R score $\leq 0$ in the LS group).

6 Non-LS, non-locomotive syndrome; LS, locomotive syndrome; $\Delta$, change from baseline to 13

7 weeks; BMI, body mass index; SMI, skeletal muscle mass index; GDS-15, Geriatric Depression

8 Scale-15; ACE-R, Addenbrooke's Cognitive Examination-Revised; Ex, daily exercise for 13

9 weeks; METs, metabolic equivalents of task. 


\section{Table 3(on next page)}

Oddsratios of characteristics for increased cognitive function ${ }^{\dagger}$ during the 13 -week study period.

Multiple logistic regression analysis adjusted for age. ${ }^{\dagger}$ increased cognitive function; D ACE-R score $>0$; NonLS, non-locomotive syndrome; LS, locomotive syndrome; Ex, daily exercise; METs, metabolic equivalents of task. 
1 Table 3:

2 Odds ratios of characteristics for increased cognitive function ${ }^{\dagger}$ during the 13-week study

3 period.

\begin{tabular}{ccccccc} 
& \multicolumn{3}{c}{ Non-LS } & & LS & \\
& OR & $95 \% \mathrm{CI}$ & $p$ & OR & $95 \%$ CI & $p$ \\
\hline $\begin{array}{c}\text { Ex } \\
\text { (METs/h/day) }\end{array}$ & 1.18 & $0.76-1.85$ & 0.460 & 5.01 & $1.30-19.24$ & $\mathbf{0 . 0 0 2}$
\end{tabular}

4 Notes. Multiple logistic regression analysis adjusted for age. †increased cognitive function;

$5 \quad \triangle$ ACE-R score $>0$; Non-LS, non-locomotive syndrome; LS, locomotive syndrome; Ex, daily 6 exercise; METs, metabolic equivalents of task.

7 


\section{Table 4 (on next page)}

Threshold of Ex values for increased cognitive function ${ }^{\dagger}$ and odds ratios (ORs) for increased cognitive function according toEx in the LS population.

\footnotetext{
${ }^{\ddagger}$ Receiver operating characteristic curve analysis was performed. ${ }^{\S}$ Multiple logistic regression analysis adjusted for age was performed. ${ }^{\dagger}$ Increased cognitive function; D ACE-R score > 0; LS, locomotive syndrome; Ex, exercise; METs, metabolic equivalents of task; $\mathrm{Cl}$, confidence interval.
} 
1 Table 4:

2 Threshold of Ex values for increased cognitive function ${ }^{\dagger}$ and odds ratios (ORs) for increased cognitive function according to

3 Ex in the LS population.

\begin{tabular}{|c|c|c|c|c|c|c|c|c|}
\hline $\begin{array}{l}\text { Threshold Ex } \\
\text { value } \\
(\text { METs } \cdot h / \text { day) }\end{array}$ & $\begin{array}{c}\text { Area } \\
\text { under } \\
\text { the curve }\end{array}$ & $\begin{array}{l}\text { Sensitivity } \\
(\%)\end{array}$ & $\begin{array}{c}\text { Specificit } \\
y \\
(\%) \\
\end{array}$ & $p$ & $\begin{array}{c}\text { Ex } \\
(\mathrm{METs} \cdot \mathrm{h} / \text { day })\end{array}$ & $\mathrm{OR}^{\S}$ & $95 \% \mathrm{CI}$ & $p$ \\
\hline \multirow[t]{2}{*}{2.29} & \multirow[t]{2}{*}{0.808} & \multirow[t]{2}{*}{80.00} & \multirow[t]{2}{*}{84.62} & \multirow[t]{2}{*}{0.047} & & 1 & \multirow{2}{*}{$\begin{array}{c}2.11- \\
228.12\end{array}$} & \multirow[t]{2}{*}{0.010} \\
\hline & & & & & $\geq 2.29$ & 21.94 & & \\
\hline
\end{tabular}

Notes. ${ }^{\star}$ Receiver operating characteristic curve analysis was performed. ${ }^{\S}$ Multiple logistic regression analysis adjusted for age was performed. Increased cognitive function; $\triangle \mathrm{ACE}-\mathrm{R}$ score $>0$; LS, locomotive syndrome; Ex, exercise; METs, metabolic equivalents of task; CI, confidence interval. 


\section{Table 5 (on next page)}

\section{Comparisonof D ACE-R scores between the two Exgroups in the LS population.}

Two-way analysis of covariance using baseline and age as the covariates. ${ }^{\dagger}$ Values are shown as means (standard deviation). LS, locomotive syndrome; Ex, exercise; METs, metabolic equivalents of task; ACE-R, Addenbrooke's Cognitive Examination-Revised; $\mathrm{h}_{\mathrm{p}}{ }^{2}$, partial eta-squared. 
1 Table 5:

2 Comparison of $\triangle \mathrm{ACE}-\mathrm{R}$ scores between the two Ex groups in the LS population.

\begin{tabular}{ccccccc}
\hline $\begin{array}{c}\text { Ex } \\
(\mathrm{METs} \cdot \mathrm{h} / \text { day })\end{array}$ & $\begin{array}{c}\text { ACE-R at } \\
\text { baseline }\end{array}$ & $\begin{array}{c}\text { ACE-R after } \\
13 \text { weeks }\end{array}$ & $\Delta$ ACE-R & $F$ & $p$ & $\eta_{\mathrm{p}}{ }^{2}$ \\
\hline $\mathrm{Ex}<2.29$ & $\begin{array}{c}89.15 \\
(11.31)^{\dagger}\end{array}$ & $86.46(10.52)$ & $-2.69(4.96)$ & 6.022 & $\mathbf{0 . 0 2 4}$ & 0.241 \\
& & & & & & \\
$\mathrm{Ex} \geq 2.29$ & $87.70(7.24)$ & $90.40(8.17)$ & $2.70(4.14)$ & & &
\end{tabular}

3 Notes. Two-way analysis of covariance using baseline and age as the covariates. $†$ Values are 4 shown as means (standard deviation).

5 LS, locomotive syndrome; Ex, exercise; METs, metabolic equivalents of task; ACE-R,

6 Addenbrooke's Cognitive Examination-Revised; $\eta_{\mathrm{p}}{ }^{2}$, partial eta-squared. 


\section{Table 6(on next page)}

\section{Comparisonof D ACE-R domain scores between the twoEx groups in the LS population.}

Two-way analysis of covariance using baseline and age as the covariates. ${ }^{\dagger}$ Values are shown as means (standard deviation). LS, locomotive syndrome; Ex, exercise; METs, metabolic equivalents of task; ACE-R, Addenbrooke's Cognitive Examination-Revised; $\mathrm{h}_{\mathrm{p}}{ }^{2}$, partial eta-squared. 
1 Table 6:

2 Comparison of $\triangle \mathrm{ACE}-\mathrm{R}$ domain scores between the two Ex groups in the LS population.

\begin{tabular}{|c|c|c|c|c|c|c|}
\hline $\begin{array}{c}\text { Ex } \\
(\text { METs } \cdot h / \text { day })\end{array}$ & $\begin{array}{c}\text { ACE-R } \\
\text { at baseline }\end{array}$ & $\begin{array}{c}\text { ACE-R } \\
\text { after } \\
13 \text { weeks }\end{array}$ & $\triangle \mathrm{ACE}-\mathrm{R}$ & $F$ & $p$ & $\eta_{\mathrm{p}}^{2}$ \\
\hline \multicolumn{7}{|c|}{ Orientation/Attention (points) } \\
\hline $\mathrm{Ex}<2.29$ & $\begin{array}{l}17.46^{\dagger} \\
(1.13)\end{array}$ & $\begin{array}{l}17.54 \\
(1.39)\end{array}$ & $\begin{array}{c}0.08 \\
(1.66)\end{array}$ & 0.020 & 0.888 & 0.001 \\
\hline$E x \geq 2.29$ & $\begin{array}{l}17.20 \\
(0.79)\end{array}$ & $\begin{array}{l}17.40 \\
(0.84)\end{array}$ & $\begin{array}{c}0.20 \\
(1.23)\end{array}$ & & & \\
\hline
\end{tabular}

Memory (points)

$\begin{array}{lcccccc}\text { Ex }<2.29 & 21.08 & 18.62 & -2.46 & 5.134 & \mathbf{0 . 0 3 5} & 0.213 \\ & (5.55) & (5.12) & (4.79) & & & \\ \text { Ex } \geq 2.29 & 18.60 & 20.70 & 2.10 & & & \\ & (5.17) & (5.08) & (2.60) & & & \end{array}$

Verbal Fluency (points)

$\begin{array}{lcccccc}\mathrm{Ex}<2.29 & 11.85 & 10.92 & -0.92 & 2.244 & 0.151 & 0.106 \\ & (2.51) & (3.64) & (2.62) & & & \\ \mathrm{Ex} \geq 2.29 & 12.60 & 12.80 & 0.20 & & & \\ & (1.51) & (1.69) & (2.62) & & & \end{array}$

Language (points)

$\begin{array}{lllllll}\mathrm{Ex}<2.29 & 24.69 & 23.92 & -0.77 & 0.063 & 0.805 & 0.003 \\ & (2.75) & (2.46) & (1.30) & & & \\ \mathrm{Ex} \geq 2.29 & 25.30 & 24.60 & -0.70 & & & \\ & (1.89) & (2.55) & (1.34) & & & \end{array}$

Visuospatial (points)

\begin{tabular}{ccccccc} 
Ex $<2.29$ & 14.08 & 15.46 & 1.38 & 2.139 & 0.160 & 0.101 \\
& $(1.19)$ & $(0.88)$ & $(1.26)$ & & & \\
Ex $\geq 2.29$ & 14.00 & 14.80 & 0.80 & & & \\
& $(1.41)$ & $(1.62)$ & $(0.92)$ & & & \\
\hline
\end{tabular}

3 Notes. Two-way analysis of covariance using baseline and age as the covariates. ${ }^{\dagger}$ Values are 4 shown as means (standard deviation).

5 LS, locomotive syndrome; Ex, exercise; METs, metabolic equivalents of task; ACE-R, 6 Addenbrooke's Cognitive Examination-Revised; $\eta_{\mathrm{p}}{ }^{2}$, partial eta-squared. 
Figure 1

Flowchart of the present study.

LS, locomotive syndrome; METS, metabolic equivalents of task.

[Measurement of variables at baseline]

0 day $(n=98)$

Exercise class (once a week)

Effort to achieve the target step count

[Measurement of daily physical activity]

[Measurement of variables at the end of the 13-week intervention]

13 weeks $(n=82)$

Excluded $(\mathrm{n}=16)$

- hospitalized $(\mathrm{n}=1)$

- discontinued $(n=15)$
Excluded $(\mathrm{n}=12)$

- lost activity meter $(n=4)$

- incomplete questionnaire

$(n=5)$

- daily activity level $\geq 7$

$\operatorname{METS} \cdot h \quad(n=3)$

\section{Analyzed $(\mathrm{n}=70)$}

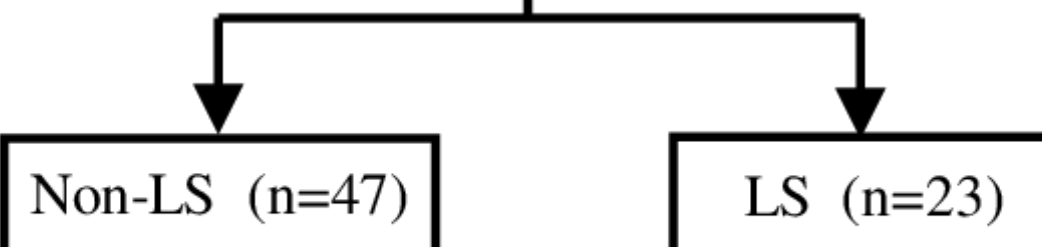

